\title{
Inhibition of $\mathrm{AT}_{1}$ receptors by losartan affects myocardial slow force response in healthy but not in monocrotaline-treated young rats
}

\author{
Oleg Lookin ${ }^{1,2}$, Alexandr Balakin ${ }^{1}$ and Yuri Protsenko ${ }^{1}$ \\ ${ }^{1}$ Laboratory of Biological Motility, Institute of Immunology and Physiology, Ural Branch of Russian Academy of Sciences, \\ 620049 Yekaterinburg, Russian Federation \\ ${ }^{2}$ Ural Federal University, 620002 Yekaterinburg, Russian Federation
}

\begin{abstract}
The slow force response (SFR) of a cardiac muscle to a sudden stretch is thought to be important in the regulatory adaptation of myocardial contraction. Autocrine-paracrine regulation pathways which involve angiotensin II are participating in this mechanism. On the other hand, renin-angiotensin-aldosterone system (RAS) is altered in hypertrophic or failing myocardium. We compared the effects of sudden stretch to SFR as well as to twitch and $\mathrm{Ca}^{2+}$ transient characteristics in rat myocardium with monocrotaline-induced heart failure with those in normal rat myocardium without and with inhibition of angiotensin II type-1 $\left(\mathrm{AT}_{1}\right)$ receptors. Our findings indicate that the myocardium of rats with monocrotaline-induced right ventricular failure is deficient with activation of local RAS and therefore expresses blunted SFR, very similar to the depression of SFR observed in normal myocardium under inhibition of $\mathrm{AT}_{1}$ receptors. The "failing" myocardium does not further respond to the "putative" inhibition of $\mathrm{AT}_{1}$ receptors by losartan. In conclusion, SFR is related to autocrine-paracrine regulation of myocardial contraction in normal rat myocardium and that the involvement of RAS into stretch-induced modulation of contractility may be significantly altered in failing heart.
\end{abstract}

Key words: Hypertrophy/heart failure - Monocrotaline - Renin-angiotensin-aldosterone system - Angiotensin II type-1 $\left(\mathrm{AT}_{1}\right)$ receptors - Slow force response $-\mathrm{Ca}^{2+}$ transient

Abbreviations: SFR, slow force response; FSM, Frank-Starling mechanism; AT, angiotensin; ET, endothelin.

\section{Introduction}

The sudden stretch of heart muscle causes rapid increase in its contractility (the Frank-Starling mechanism) followed by the slow force response (SFR). The SFR in mammalian myocardium is attributed to a long-term adaptation of the heart to environmental conditions and confirmed in many mammals including human, and on different levels of myocardial tissue - from single cell to whole organ (Hongo et al. 1996; Kentish and Wrzosek 1998; Todaka et al. 1998; von

Correspondence to: Oleg Lookin, Laboratory of Biological Motility, Institute of Immunology and Physiology, Ural Branch of Russian Academy of Sciences, bldg 106, Pervomayskaya st, 620049 Yekaterinburg, Russian Federation

E-mail: o.lookin@iip.uran.ru
Lewinski et al. 2003; Calaghan and White 2004; von Lewinski et al. 2004; Kockskämper et al. 2008).

The exact mechanisms of SFR remain unclear but they require slow change in cytosolic $\mathrm{Ca}^{2+}$ (Cingolani et al. 2013; Shen et al. 2013). It has been proposed initially that $\mathrm{Ca}^{2+}$ entry into a cell is elevated in stretched myocardium due to the stretch-activated channels (Zeng et al. 2000; Calaghan and White 2004). Transient receptor potential cation channels (TRPCs) are also stretch-sensitive and therefore may facilitate $\mathrm{Ca}^{2+}$ entry in the response to mechanical stress (Barritt and Rychkov 2005; Yamaguchi et al. 2018), as well as stretch-induced changes in phosphorylation of regulatory proteins of the contractile filaments (Monasky et al. 2010). Another pathway is the stretch-initiated increase in metabolic demand and stimulation of $\mathrm{Na}^{+}$entry via both sodium-hydrogen exchanger $(\mathrm{NHE})$ and $\mathrm{Na}^{+} / \mathrm{HCO}^{3-}$ 
transporters with subsequent activation of sodium-calcium exchanger (NCX) in reverse mode and $\mathrm{Ca}^{2+}$ accumulation in a cell (Bluhm et al. 1998; Shen et al. 2013). More complex mechanism of autocrine-paracrine regulation in the response to stretch has been recently proposed: release of angiotensin II (Ang II) $\rightarrow$ activation of Ang II type-1 receptors $\left(\mathrm{AT}_{1}\right.$ receptors $) \rightarrow$ activation of $\mathrm{NHE}-1 \rightarrow$ activation of NCX in reverse mode and $\mathrm{Ca}^{2+}$ accumulation in the cell (Pérez et al. 2003, 2011; Vargas et al. 2013). Accordingly to recent studies, mineralocorticoids are also involved into activation of NHE-1 via control of redox-sensitive kinases; inhibition of mineralocorticoid receptors therefore affects the above mentioned autocrine-paracrine mechanism of slow force response (Ennis et al. 2013; Díaz et al. 2014).

The slow adaptation of myocardial contractility is altered under hypertrophy or heart failure. Moreover, the progression of cardiac hypertrophy involves the same mechanisms as of SFR, e.g. the release of endogenous Ang II and/or endothelin and further activation of $\mathrm{AT}_{1}$ receptors in stretched myocardium (Ito et al. 1993; Sadoshima et al. 1993; Malhotra et al. 1999; Pérez et al. 2003; Cingolani et al. 2011). Moreover, stretch may trigger the activation of $\mathrm{AT}_{1}$ receptors without release of Ang II (Yasuda et al. 2008). Other mechanisms like TRPCs may also contribute to the pathological remodeling in sustained hypertension, affecting cell hypertrophic signaling triggered by Ang II or ET-1 (Seo et al. 2014). Since SFR is originated at least in part from some of these mechanisms, slow changes in contractility in pathology may substantially differ from their typical shape/extent observed in normal myocardium.

Therefore, we were motivated to evaluate the effect of depletion of local renin-angiotensin system (RAS) by inhibition of $\mathrm{AT}_{1}$ receptors on the background of systemic upregulation of RAS in monocrotaline-treated rats with right ventricular failure. We compared stretch-induced slow changes in twitch and $\mathrm{Ca}^{2+}$ transient characteristics in right ventricular myocardium of monocrotaline-treated rats with those obtained in normal myocardium without and with inhibition of $\mathrm{AT}_{1}$ receptors in order to elucidate a role of RAS in slow adaptation of contractility in diseased myocardium.

\section{Materials and Methods}

\section{Ethical approval}

The authors assure that the animal experiments were carried out in accordance with EU regulations (86/609/EEC) and the use of the animals was reviewed and approved by the local Institutional Ethics Committee. Rats were obtained from the Institutional Animal House and maintained under a $12 \mathrm{~h}$ light-dark cycle with free access to standard chow and water.

\section{Experimental model of monocrotaline-induced heart failure}

Monocrotaline was used to develop pulmonary hypertension followed by severe right ventricular hypertrophy. Briefly, 4-week-old Wistar rats of both sexes (weighing 80-100 g) were randomly divided into control (normal myocardium) and monocrotaline-treated (hypertrophic myocardium) groups. Rats in monocrotaline-treated group were given a single subcutaneous injection of saline solution containing monocrotaline $(2 \mathrm{ml} / \mathrm{kg}$; final concentration $50 \mathrm{mg} / \mathrm{kg}$ body weight), whereas rats in the control group were injected with an equivalent volume of saline solution. Monocrotalinetreated rats $(n=37$ in total) were killed as soon as loss of body weight and dyspnea at rest became prominent $(23.3 \pm$ 0.5 days after treatment). Control rats ( $n=22$ in total) were killed at the same age. The validity of the experimental model of pulmonary hypertension and severe hypertrophy/heart failure in young rats has been tested and confirmed in our recent study (Lookin et al. 2015b). The above described treatment induced substantial increase in right ventricular mass by $50 \%$ with significant loss of left ventricular mass by 30\% indicating a marginal state between severe hypertrophy and heart failure. For a reason of uniformity, elsewhere in the text we use term "failing" to refer this state of the myocardium.

\section{Muscle isolation}

Animals were anaesthetized with $15 \mathrm{mg} / \mathrm{kg}$ zolazepam (Zoletil100 ${ }^{\circledR}$; Virbac, Carros, France) and killed by rapid cervical dislocation. The heart was quickly excised and placed in modified Krebs-Henseleit (K-H) solution (in mM: $\mathrm{NaCl}$ 118.5; $\mathrm{KCl} 4.2 ; \mathrm{MgSO}_{4}$ 1.2; $\mathrm{CaCl}_{2}$ 2.5; glucose 11.1) equilibrated in $95 \% \mathrm{O}_{2}+5 \% \mathrm{CO}_{2}$ with $\mathrm{NaHCO}_{3}$ and $\mathrm{KH}_{2} \mathrm{PO}_{4}$ to maintain $\mathrm{pH}$ at 7.35. Papillary muscles were dissected from the right ventricle, clipped to force transducer and length servomotor (Muscle Research System; Scientific Instruments $\mathrm{GmbH}$, Heidelberg, Germany) in experimental bath and continuously bathed in $\mathrm{K}-\mathrm{H}$ solution. The mean diameter of the used muscles was $258 \pm 22 \mu \mathrm{m}$ for normal heart $(n=$ 22; 6 males/16 females) vs. $316 \pm 23 \mu \mathrm{m}$ for failing heart ( $n=37,16$ males/21 females). Force and length (as well as fura-2 intensity in several measurements, see below) were sampled at $10 \mathrm{kHz}$ using an analog-to-digital (A/D) and D/A data converter (PCI-1716S; AdLink Technology, New Taipei City, Taiwan) and custom-made software running in a real-time environment (HyperKernel; Nematron, Ann Arbor, MI, USA) integrated with Windows XP (Microsoft; Redmond, WA, USA). Data were processed and analysed off-line using custom-made software. All experiments were carried out at $25^{\circ} \mathrm{C}$ and pacing rate of $0.33 \mathrm{~Hz}$. All chemicals were purchased from Sigma-Aldrich (St. Louis, MO, USA) except potassium losartan (Merck Sharp \& Dohme Corp, Haarlem, The Netherlands). 


\section{Experimental protocols}

A muscle was released to the length where no passive force was developed; this length was assumed as slack length. The muscle was then stretched gradually for approximately 2-3\% of the slack length and allowed to equilibrate at the new length prior to further measurements. When no further increase in the amplitude of active tension was observed, the final length was assumed as $L_{M A X}$. A protocol of sudden stretch of isometrically contracting muscle from $85 \%$ to $95 \% L_{M A X}$ was applied to measure slow changes in contractile activity of a muscle, i.e. slow force response (SFR), slow twitch-totwitch changes in certain characteristics. Rapid stretch event lasted $\sim 100 \mathrm{~ms}$ and muscle contractions at the new length were recorded continuously during 5 or 10 minutes. If necessary, the protocol was repeated 2 or 3 times more, every time a muscle was released and kept at $85 \% L_{M A X}$ during 5-10 min prior to the next stretch. Averaged slow response in a muscle was obtained from individual responses. To compare the expression of slow changes in contractility between individual muscles, we normalized the value of given characteristics in each twitch to the value obtained in first twitch after stretch (T2 value, see Fig. 1A).

We also examined the effect of inhibition of $\mathrm{AT}_{1}$ receptor on the expression of slow changes in contractility in the myocardium of control and monocrotaline-treated rats. The slow responses were measured in standard $\mathrm{K}-\mathrm{H}$ solution, then a selective inhibitor of $\mathrm{AT}_{1}$ receptors $(100 \mu \mathrm{mol} / \mathrm{l}$ losartan) was added to the solution and the measurements were repeated 30 min later. For some of the measurements in normal myocardium, free cytosolic $\mathrm{Ca}^{2+}$ was monitored simultaneously with isometric twitch by fluorescent indicator fura-2 added into the solution in its cell-permeating form (5 $\mu \mathrm{M}$ fura-2/AM + 5\% w/v Pluronic F-127). Fura-2 signals were obtained as a ratio of light intensities collected at $510 \mathrm{~nm}$ wavelength by excitation at either $340 \mathrm{~nm}$ or $380 \mathrm{~nm}\left(F=F_{340} / F_{380}\right)$ and presented here as $F / F 0$, where $\mathrm{FO}$ is a ratio measured in quiescent muscle at slack length (i.e. when no stretch is applied).

\section{Statistical analysis}

Results are presented as means \pm SEM. Differences in twitch/ $\mathrm{Ca}^{2+}$ transient characteristics between normal and "failing" myocardium obtained in the time-matched manner during stretch protocol (i.e. before stretch, immediately after stretch, at the end of response) were evaluated by one-way ANOVA followed by the Newman-Keuls test. Differences in the time-matched data obtained in the absence and presence of losartan in the saline were tested by two-way ANOVA. Effects were considered significant at $p<0.05$.

\section{Results}

Slow response of contractility in normal and "failing" rat myocardium

Table 1 summarizes the mean values of characteristics of single isometric twitch measured in right ventricular myocardium of control and monocrotaline-treated rats before, immediately after, and at the end of slow response to rapid stretch. Note that "failing" rat myocardium was significantly weaker compared to normal myocardium under steadystate conditions (e.g. before stretch or at the end of slow response to stretch). Immediately after the stretch, mean values of peak active tension were not significantly different between normal vs. "failing" myocardium (45.2 \pm 4.7 vs. 34.4

\section{A}

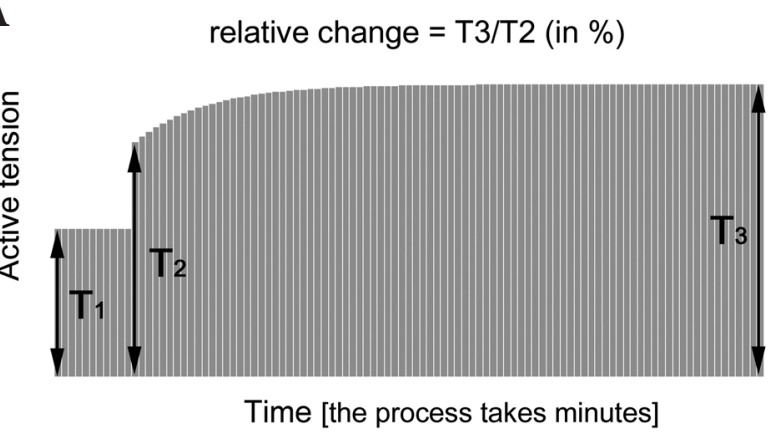

B

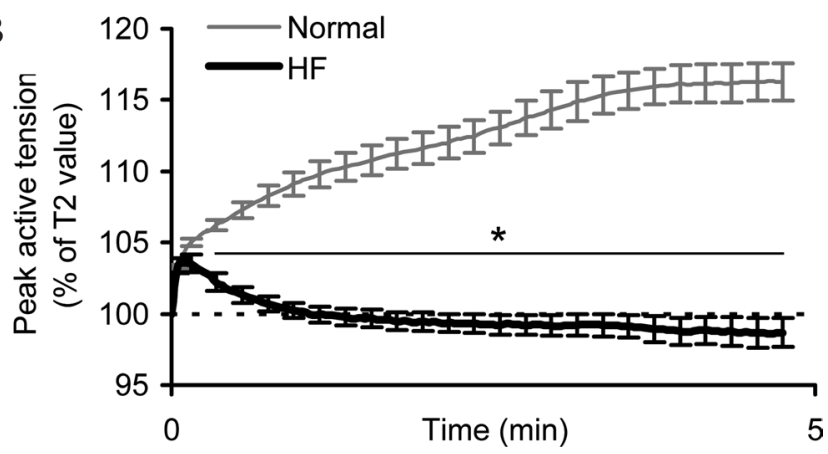

Figure 1. Slow force response to rapid stretch. A. Typical scheme of slow changes in twitch amplitude developed after rapid stretch of a muscle. $T_{1}$, twitch amplitude before stretch; $T_{2}$, twitch amplitude immediately after stretch; $T_{3}$, twitch amplitude at the end of slow changes. The visual representation of this scheme is based on the figure from (Bluhm et al. 1998). B. Slow changes in peak active tension measured in normal and "failing" (HF) rat myocardium after rapid stretch of a muscle from $85 \%$ to $95 \% L_{M A X}$, presented in a $\%$ of T2 value; dashed line shows T2 level. Data in panel B are presented as mean \pm S.E.M, the range for significant difference in time-matched change between normal and failing myocardium is marked by horizontal line with asterisk $(p<0.05)$. 
Table 1. The characteristics of single isometric twitch measured before, immediately after, and at the end of slow response to sudden stretch in right ventricular papillary muscles isolated from control (normal myocardium) and monocrotaline-treated (heart failure) rats

\begin{tabular}{|c|c|c|c|c|c|c|}
\hline & \multicolumn{3}{|c|}{ Normal myocardium $(n=10)$} & \multicolumn{3}{|c|}{ Heart failure $(n=16)$} \\
\hline & before & after & end & before & after & end \\
\hline Peak active tension & $16.4 \pm 2.3^{*}$ & $45.2 \pm 4.7$ & $52.2 \pm 5.1^{\star}$ & $10.6 \pm 1.2$ & $34.4 \pm 2.5$ & $34.0 \pm 2.6$ \\
\hline $\mathrm{dT} / \mathrm{dt}(\mathrm{dev})$ & $198 \pm 26^{*}$ & $449 \pm 43^{*}$ & $559 \pm 52^{*}$ & $98 \pm 11$ & $294 \pm 22$ & $304 \pm 24$ \\
\hline $\mathrm{dT} / \mathrm{dt}(\mathrm{dec})$ & $91 \pm 11$ & $180 \pm 18$ & $202 \pm 20$ & $61 \pm 7$ & $164 \pm 13$ & $157 \pm 13$ \\
\hline TTP & $158 \pm 3^{*}$ & $187 \pm 4^{*}$ & $171 \pm 3^{*}$ & $206 \pm 5$ & $220 \pm 6$ & $209 \pm 5$ \\
\hline T50 & $119 \pm 5$ & $177 \pm 7$ & $176 \pm 7$ & $127 \pm 4$ & $167 \pm 6$ & $167 \pm 5$ \\
\hline
\end{tabular}

Peak active tension, in $\mathrm{mN} / \mathrm{mm}^{2}$; $\mathrm{dT} / \mathrm{dt}(\mathrm{dev})$, maximal rate of rising phase of isometric twitch (development) - absolute values in $\mathrm{mN} / \mathrm{mm}^{2}$ per second; $\mathrm{dT} / \mathrm{dt}(\mathrm{dec})$, maximal rate of isometric twitch decline - absolute values $\mathrm{mN} / \mathrm{mm}^{2}$ per second; TTP, time from the onset of stimulus to peak active tension (ms); T50, time interval of decline from peak active tension to half-amplitude of peak tension (ms). The slow responses were monitored during 5 minutes. * significant difference between normal and "failing" myocardium at the same stage of slow response $(p<0.05)$.

$\pm 2.5 \mathrm{mN} / \mathrm{mm}^{2}$, respectively). The rising phase of twitch (tension development) was always substantially slower and prolonged in the "failing" myocardium, regardless the stage of slow response. However, the maximal rate of tension decline during relaxation phase, if expressed in absolute values, was not significantly different between normal and "failing" myocardium. As similar, time to decline from peak tension to half-amplitude (T50) was not different between normal and "failing" myocardium at either stage of slow response.

We further compared relative changes in slow response of twitch amplitude between normal and "failing" rat myocardium. For the given slow response, peak active tension was measured immediately after stretch (T2) and at the end of response (T3, Fig. 1A). The absolute changes in the active tension during slow response were therefore evaluated as a $\%$ of $\mathrm{T} 2$ value. While rapid stretch induced similar relative increase in peak active tension in normal and "failing" myocardium during several twitches immediately after stretch, further changes were significantly different both in the extent and shape (Fig. 1B). The myocardium of untreated rats developed positive response, in contrast to "failing" myocardium of MCT-treated rats where slow depression of peak active tension back to T2 value was observed. At the end of response, the muscles from control and monocrotalinetreated rats developed $116.3 \pm 1.3 \%$ and $98.7 \pm 1.0 \%$ of $\mathrm{T} 2$ value, respectively (difference is significant, $p<0.05$ ).

\section{Effect of inhibition of angiotensin II type-1 $\left(A T_{1}\right)$ receptors on slow response of contractility in normal and "failing" rat myocardium}

It has been conceived that slow force response in normal myocardium is regulated by complex pathway of molecular event involving Ang II/endothelin secretion (Alvarez et al. 1999; Cingolani et al. 2013). To test whether the pathway is in operation under our experimental conditions, we compared twitch characteristics during slow responses to stretch in normal rat myocardium before and after inhibition of $\mathrm{AT}_{1}$ receptors by perfusion of muscles with modified Krebs-Henseleit solution $+100 \mu \mathrm{mol} / 1$ losartan for $30 \mathrm{~min}$ $(n=12)$. This set of measurements utilized separate pool of muscles not involved into calculations presented in Table 1.

For some of the muscles, $\mathrm{Ca}^{2+}$ transients were simultaneously measured in 30-s intervals every 2 min during 10 -min response to sudden stretch $(n=7)$. In this set of measurements we checked whether the slow changes in peak tension are accompanied by slow changes in the kinetics of free cytosolic calcium. Some previous reports (Hongo et al. 1996; Kentish and Wrzosek 1998; Calaghan and White 2004; Shen et al. 2013; Yamaguchi et al. 2018) showed that the slow stretch-related increase in contractility develops in parallel to the slow amplification of peak systolic calcium. We hypothesize that the characteristics of $\mathrm{Ca}^{2+}$ transient decline, rather than its amplitude, may be more effective in evaluation of slow changes in $\mathrm{Ca}^{2+}$ utilization by contractile machinery and therefore slow development of extra force. As reported previously in (Kentish and Wrzosek 1998; Lookin et al. 2015a, 2015b), the shape of $\mathrm{Ca}^{2+}$ transient decay in a rat ventricular cardiomyocytes strongly depends on the extent of muscle stretch. The larger stretch the more prominent is the phase of short-term deceleration of $\mathrm{Ca}^{2+}$ transient decay, i.e. "bump". At any stretch applied, one can evaluate the extent of the "bump" by measuring its amplitude and/ or integral intensity (for methodological details see (Lookin et al. 2015a, 2015b)). Moreover, it is conceiving that under steady-state contraction the prominence of the "bump" (e.g. evaluated as integral intensity) is strongly and positively correlated to the amplitude of contraction. Therefore, we evaluated how closely are related the slow force changes and the slow changes in the integral intensity of the "bump". To complete this, the $\mathrm{Ca}^{2+}$ transients were averaged in $30 \mathrm{~s}$ intervals measured immediately after stretch and then every 
2 min during the response. Next, the "bump" was extracted from every averaged $\mathrm{Ca}^{2+}$ transient. At any time interval ( 0 , 2, 4, 6, 8 and 10 min after stretch), the integral intensity of the bump was evaluated relatively to the integral intensity of monotonously declined $\mathrm{Ca}^{2+}$ transient (area under the transient trace minus "bumped" part) and then expressed in a $\%$ of this value obtained immediately after stretch.

The examples of $\mathrm{Ca}^{2+}$ transients measured in right ventricular myocardium of normal and monocrotaline-treated rats during the slow force response in different conditions, e.g. in losartan-free or losartan-containing solution, are shown in Fig. 2. These experimental records demonstrate that $\mathrm{Ca}^{2+}$ transient decline may reveal slow modification in its shape during the slow response to rapid stretch. The slow changes were more expressed in normal vs. failing myocardium (compare Fig. 2A and 2B) which correlates with more pronounced slow changes in contractility. Therefore we performed quantitative evaluation of this correlation between peak tension and cytosolic calcium.

The perfusion of myocardial preparations from normal hearts in losartan-containing medium was not followed by significant change in absolute values of twitch amplitude or duration, compared to the losartan-free solution, either in pre-stretch condition (at 85\% $L_{M A X}$ ), immediately after stretch to $95 \% L_{M A X}$, or at the end of slow response; e.g, mean absolute values of peak active tension in case of absence/pres- ence of losartan in the saline were equal to, respectively, 15.6 $\pm 3.3 / 18.2 \pm 3.7 \mathrm{mN} / \mathrm{mm}^{2}$ before stretch, $38.3 \pm 7.7 / 42.6 \pm$ $8.0 \mathrm{mN} / \mathrm{mm}^{2}$ immediately after stretch, and $42.1 \pm 8.2 / 40.8$ $\pm 7.9 \mathrm{mN} / \mathrm{mm}^{2}$ at the end of slow response (differences are non-significant between absence/presence of losartan at any stage). $\mathrm{Ca}^{2+}$ transient end-diastolic level displayed no change either with stretch or application of losartan, while end-systolic level was slightly elevated in losartan-containing saline regardless the extent of stretch, e.g. $1.44 \pm 0.09 v s .1 .52$ $\pm 0.15 \mathrm{~F} / \mathrm{F}_{0}$ at $85 \% L_{M A X}, 1.45 \pm 0.11$ vs. $1.50 \pm 0.15 \mathrm{~F} / \mathrm{F}_{0}$ under steady-state condition at $95 \% L_{M A X}$ in losartan-free and losartan-containing saline, respectively (no significant difference). As similar, $\mathrm{Ca}^{2+}$ transient time-to-peak was somewhat higher in the losartan-perfused muscles at any extent of stretch, e.g. $68.9 \pm 9.8$ vs. $85.6 \pm 15.6 \mathrm{~ms}$ at $85 \%$ $L_{\text {MAX }}, 56.2 \pm 6.3$ vs. $63.5 \pm 8.9$ ms under steady-state condition at $95 \% L_{M A X}$ in losartan-free and losartan-containing saline, respectively (no significant difference).

While application of losartan in normal myocardium induced virtually no changes in the steady-state isometric twitch and $\mathrm{Ca}^{2+}$ transient, it resulted in significant depression of stretch-induced slow increase in peak active tension in the normal rat myocardium. Thus, at the end of 10-min interval after sudden stretch the peak active tension was $112.7 \pm 2.0 \%$ of $\mathrm{T} 2$ value (i.e. immediately after stretch) in losartan-free solution but only $96.8 \pm 2.3 \%$ of $\mathrm{T} 2$ value in

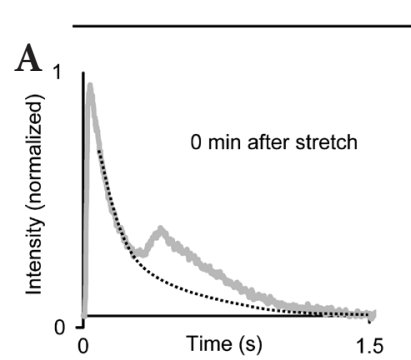

Losartan-free solution
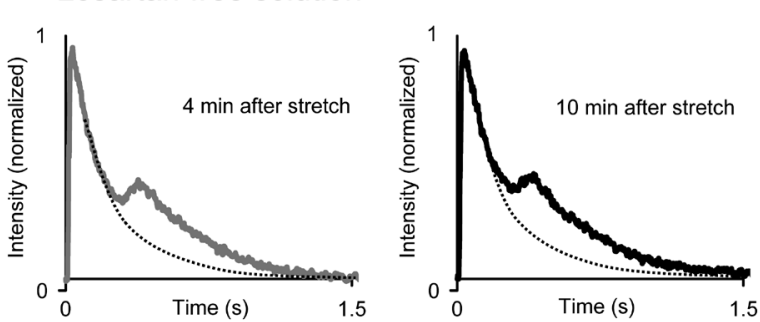

$100 \mu \mathrm{M}$ Losartan
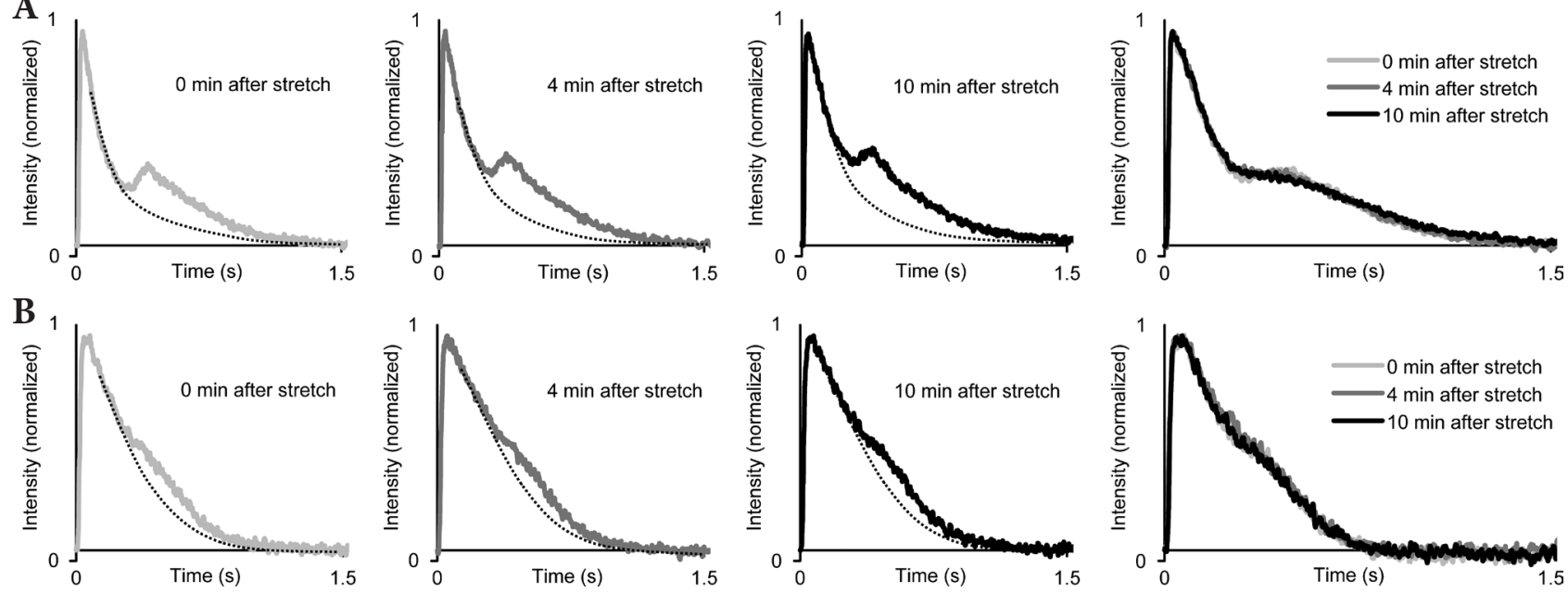

Figure 2. The stretch-induced slow changes in the shape of $\mathrm{Ca}^{2+}$ transient in right ventricular myocardium of normal and monocrotalinetreated rats after rapid stretch of a muscle from $85 \%$ to $95 \% L_{M A X}$ under perfusion in saline without and with $100 \mu \mathrm{M}$ losartan. A. Ca ${ }^{2+}$ transients obtained in a trabecula of normal rat immediately after stretch $(0 \mathrm{~min})$ and after 4 and 10 minutes after the stretch in losartanfree saline. Dotted line shows monotonic component of $\mathrm{Ca}^{2+}$ transient decline; the difference between the original and monotonic traces is the "bump" component. The last plot in panel A shows superimposed $\mathrm{Ca}^{2+}$ transients obtained in the same muscle for the same time points after rapid stretch under perfusion in $100 \mu \mathrm{M}$ losartan in saline. B. $\mathrm{Ca}^{2+}$ transients obtained in a trabecula of monocrotaline-treated rat. The plot composition is the same as in panel A. $\mathrm{Ca}^{2+}$ transients are normalized to their respective peak. Note prominent "bump" in the muscle from normal rat whereas much less "bump" is observed in the muscle from monocrotaline-treated rat. 
A

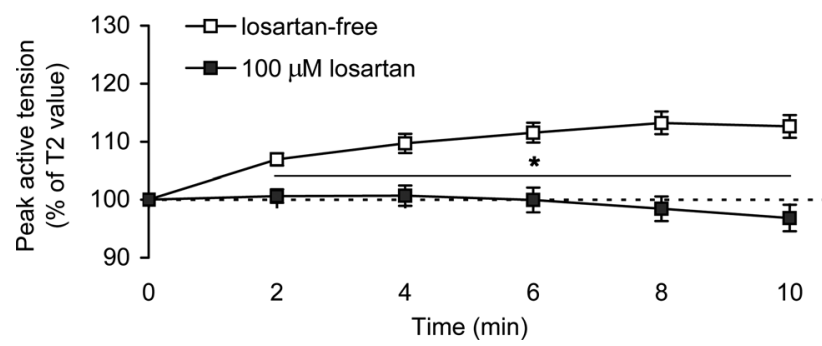

B

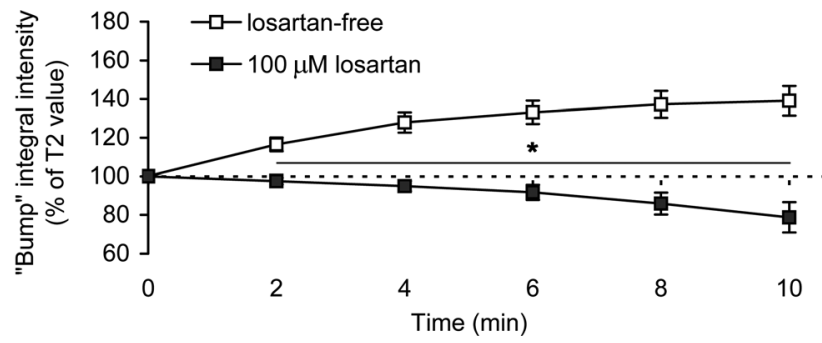

Figure 3. The effect of losartan on the slow changes in peak active tension and relative integral intensity of $\mathrm{Ca}^{2+}$ transient "bump" in normal rat myocardium after rapid stretch of a muscle from $85 \%$ to $95 \% L_{M A X}$ under perfusion in saline without and with $100 \mu \mathrm{M}$ lo$\operatorname{sartan}$ ( $n=12$ for mechanics, $n=7$ for "bump" measurements). A. Peak active tension. B. Relative integral intensity of "bump". Changes are presented in a \% of value measured immediately after stretch (T2 value), dashed line shows T2 level. Data are presented as mean \pm S.E.M, the range for significant difference in time-matched change between absence and presence of losartan in the saline is marked by horizontal line with asterisk $(p<0.05)$.

the presence of $100 \mu \mathrm{mol} / 1$ losartan in solution (significant difference at $p<0.05$, Fig. $3 \mathrm{~A})$. Note that this losartaninduced depression of slow increase in peak tension is quantitatively similar to that observed between normal and "failing" myocardium under perfusion with losartan-free saline (compare Fig. 3A and Fig. 1B).

Surprisingly, $\mathrm{Ca}^{2+}$ transient peak systolic and enddiastolic levels showed no changes during the slow response both in losartan-free and losartan-containing solution (the respective values at the end of response are given as \% of T2 value; end-diastolic level: $100.0 \pm 0.1$ and $100.0 \pm 0.2 \%$; peak systolic level: $99.5 \pm 1.5$ and $99.2 \pm 0.9 \%)$. In contrast, the relative integral intensity of the "bump" progressively increased during 10-min slow force response in losartanfree solution (up to $139.1 \pm 7.7 \%$ of $\mathrm{T} 2$ value) but the prominent decrease was observed in losartan-containing medium (to $78.7 \pm 7.9 \%$, Fig. $3 \mathrm{~B}$ ). These changes in the integral intensity of the $\mathrm{Ca}^{2+}$ transient "bump" were in close semblance to the changes in the peak active tension developed during the slow response to stretch (compare Fig. 3B and Fig. 3A).

The impairment of angiotensin II involving pathway in "failing" myocardium may explain drastic depletion of slow force response as observed in muscles from monocrotalinetreated rats (see Fig. 1B). If so, the application of losartan would make no effect on the slow force changes. Moreover, the lack of slow changes in force should imply no or minor slow changes in the integral intensity of "bump". To confirm this, we tested effects of inhibition of $\mathrm{AT}_{1}$ receptors on slow response in the muscles isolated from the hearts of monocrotaline-treated rats with right ventricular failure. Preparations different from those shown in Fig. 1B were used in this separate set of measurements $(n=21)$; the twitch characteristics of both sets of the muscles were not different. For some of the muscles, $\mathrm{Ca}^{2+}$ transients were simultaneously measured in 30-s intervals every 2 min during 10-minute response to sudden stretch to retrieve slow changes in the "bump" characteristics $(n=6)$.

Application of losartan in the "failing" myocardium had no effect on absolute characteristics of isometric twitch; e.g, mean value of peak active tension in absence $v s$. presence of losartan in the saline was amounted to, respectively, $14.4 \pm 3.2 v s .16 .9 \pm 3.7 \mathrm{mN} / \mathrm{mm}^{2}$ before stretch, $37.0 \pm$ 2.9 vs. $37.1 \pm 3.0 \mathrm{mN} / \mathrm{mm}^{2}$ immediately after stretch, and $36.1 \pm 2.9$ vs. $35.5 \pm 2.8 \mathrm{mN} / \mathrm{mm}^{2}$ at the end of response. If evaluated in terms of T2 value, the peak active tension at the end of response amounted to $97.5 \pm 1.5 \%$ and $96.0 \pm$ $1.9 \%$ of $\mathrm{T} 2$ value in losartan-free and losartan-containing saline, respectively (Fig. 4A). As similar, the slow changes in the relative integral intensity of $\mathrm{Ca}^{2+}$ transient "bump" were found to be insensitive to losartan and amounted to $87.1 \pm 4.3 \%$ and $88.2 \pm 2.8 \%$ of $\mathrm{T} 2$ value in losartan-free and losartan-containing saline, respectively (Fig. 4B). Note that paralleled changes in contractility and "bump" integral intensity were still observed in the "failing" myocardium. This strongly supports the idea that characterization of stretch-induced effects on $\mathrm{Ca}^{2+}$ transient decline may provide useful information about calcium-induced modulation of contractility.

\section{Discussion}

The slow force response (SFR) of a heart muscle to rapid stretch is pronounced in the right ventricular myocardium of healthy rats, in contrast to the myocardium of monocrotaline-treated rats with developed right ventricular failure ("failing" myocardium). In the present study we found that the extent of SFR depression in the "failing" rat myocardium was similar to that observed in normal rat myocardium with inhibited $\mathrm{AT}_{1}$ receptors by losartan. Our results are in good accordance with the conception that slow force response 
A

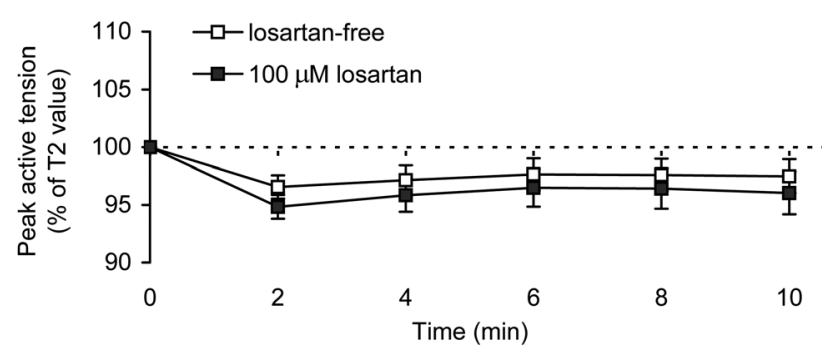

B

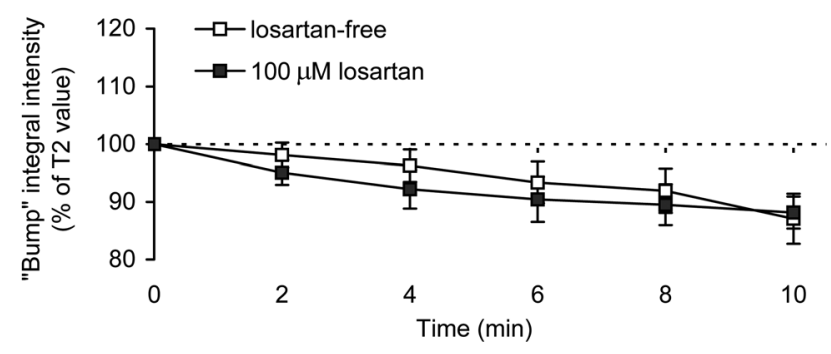

Figure 4. The effect of losartan on the slow changes in peak active tension and relative integral intensity of $\mathrm{Ca}^{2+}$ transient "bump" in the myocardium of monocrotaline-treated rats with right ventricular failure after rapid stretch of a muscle from $85 \%$ to $95 \% L_{M A X}$ under perfusion in saline without and with $100 \mu \mathrm{M} \operatorname{losartan}$ ( $n=12$ for mechanics, $n=7$ for "bump" measurements). A. Peak active tension. B. Relative integral intensity of "bump". Changes are presented in a \% of value measured immediately after stretch (T2 value), dashed line shows $\mathrm{T} 2$ level. Data are presented as mean \pm S.E.M.

is regulated via activation of $\mathrm{AT}_{1}$ receptors by endogenous Ang II in normal cardiomyocytes and support that a common mechanism is participating in the deficiency of SFR in "failing" myocardium and in normal myocardium with altered function of key player(s) in autocrine-paracrine mechanism of stretch-related force regulation (Cingolani et al. 2011; Pérez et al. 2011; Cingolani et al. 2013). Our data about the depression of SFR in the myocardium of rats with heart failure are in agreement with recent report (von Lewinski et al. 2009) where SFR in failing human myocardium was little expressed. Therefore, activation of $\mathrm{AT}_{1}$ receptors is thought to be important mechanism of slow adaptation of ventricular contractility in mammalian hearts. Interestingly, the SFR is not observed in cardiac muscles with already elevated levels of Ang II prior to stretch (Neves et al. 2013). Therefore, the lack of the effect of losartan on slow force changes in the myocardium of monocrotaline-treated rats may reflect either the silencing of angiotensin secretion or augmented activation of $\mathrm{AT}_{1}$ receptors under pathological remodeling of cardiac cell in this model of right ventricular failure. A direct effect of losartan on metabolic processes like glucose oxidation, as recently reported in fat cells (Caminhotto et al. 2016), is hardly believed in the muscles because of the great suppression of SFR in normal myocardium under perfusion by losartan and the absence of this effect in "failing" muscles.

Authors note that our ambient conditions were out of physiological. Our primary goal was to study the phenomenon of slow force response and to provide direct data on its preservation/disappearance in failing myocardium. Fast stimulation (but still limited to $2-2.5 \mathrm{~Hz}$ in the most of reported biophysical studies) and physiological temperature extremely accelerates the processes involved into generation of slow changes in force after rapid length change. For instance, subphysiological conditions strongly affect $\mathrm{Ca}^{2+}$ kinetics in cardiomyocytes (both in single twitch and in cycle-to-cycle changes). It becomes hard to monitor such changes if they are fast and quite minor. Moreover, persistent physiological conditions affect the stability of $\mathrm{Ca}^{2+}$ indicators so prolonged fluorescent measurements in these conditions (>30-60 minutes) are not achievable.

Also, we used much higher concentration of losartan in the present study if compared to other reports. The reason is that we found less consistent effects at lower concentrations $(1$ and $10 \mu \mathrm{M})$ in terms of incomplete depression of slow force response. The largest concentration we used in the preliminary set of measurements $(100 \mu \mathrm{M})$ was effective and completely abolished slow force response. The difference between our conditions and the others may originate from different suppliers/manufacturers (we used Merck Sharp \& Dohme while other groups used Sigma) as well as different animal species (Thomas et al. 1996; Cingolani et al. 1998). Also, losartan acts in dose-dependent manner and the effective concentration of losartan depends on the actual level of Ang II (Shao et al. 1998).

In contrast to some previous reports (Hongo et al. 1996; Kentish and Wrzosek 1998; Calaghan and White 2004; Yamaguchi et al. 2018) we did not observe paralleled changes in peak active tension and end-diastolic or end-systolic level of $\mathrm{Ca}^{2+}$ transient in normal rat myocardium bathed in losartan-free or losartan-containing solution. However, we found that stretch-induced slow changes in peak active tension are highly conformed to the changes in $\mathrm{Ca}^{2+}$ transient decay morphology, specifically to the phase of brief deceleration of this decay ("bump"). In particular, the strong conformity between slow changes in peak contraction and "bump" integral intensity was observed both in normal and "failing" myocardium either in losartan-free or losartancontaining conditions. We conclude that slow changes in $\mathrm{Ca}^{2+}$ transient decline, rather than in its amplitude or peak level, may relate more closely to the stretch-induced development of contraction. 
It is well documented in numerous studies that rapid increase in contractility occurred immediately after stretch is typical in mammalian myocardium. This instant force potentiation is thought to be attributed to the changes in interfilament overlap and affinity of regulatory protein troponin $\mathrm{C}$ to $\mathrm{Ca}^{2+}$ ions (the Frank-Starling mechanism, FSM). The FSM is not vanished completely in failing rat myocardium, as similar to the previously published findings in failing human myocardium (von Lewinski et al. 2009), yet blunted substantially accordingly to our recent studies (Lookin et al. 2015a, 2015b). Currently, there are numerous evidences that adaptation of heart to the changes in load involves both fast and slow mechanisms (FSM) which are interrelated during global regulation of pump function of a whole heart. For instance, slow diastolic filling of ventricular chamber involves the stretch of myocardial fibers (FSM) while longlasting elevation of intraventricular pressure may trigger the epigenetic mechanism of development of physiological (cyclic changes in the load) or pathological (constantly elevated load) hypertrophy (van Wamel et al. 2000). From this point of view it is important to note that some therapies of heart failure inhibition of angiotensin-converting enzyme and angiotensin receptor (Abraham et al. 2003) or mineralocorticoid receptors (Ennis et al. 2013) - while useful in the treatment of arterial hypertension, must nevertheless take into account possible side-effects on the slow force response as a regulatory pathway of myocardial contraction.

At last, the present study has been done with impuberal rats of both sexes and we did not found sex-related differences in slow responses either in healthy or in monocrotaline-treated rats. The myocardium of adult rats might still have sex-specific regulation of slow response since sex hormones play important role in the preservation of the Frank-Starling mechanism under heart failure in female myocardium (Ahn et al. 2003; Bal et al. 2013; Lookin et al. 2015a). Further sex-oriented study of the mechanisms of fast and slow regulation of contraction is needed to clarify the role of sex hormones in the middle- or long-term control of myocardial function.

In summary, our results support that there is a common feature between the mechanism(s) of slow force response in normal myocardium and the mechanism(s) of development of monocrotaline-induced severe hypertrophy or heart failure in rats. This feature is the activation of angiotensin type 1 receptors. In normal rat myocardium, this mechanism triggers NHE-1 involving pathway of slow regulation of contractility (Cingolani et al. 2011). The depression of slow force response in the failing rat myocardium might be related to diminished effectiveness of the stretch-induced endogenous release of angiotensin on the background of elevated level of exogenous angiotensin developed in hypertrophy; the endogenous release may also be blocked in this pathological state.
Acknowledgements. Authors thank Daniil Kuznetsov for his help in the implementation of the monocrotaline-based experimental model of pulmonary hypertension in rats. The work was conducted in IIP UB RAS accordingly to the officially registered plan of scientific investigations (\#AAAA-A18-118020590031-8) and was supported by Russian Foundation for Basic Research (grant \#16-0400545) and the Program for Basic Research of Ural Branch of the Russian Academy of Sciences for 2015-2017 (project \#15-5-4-6).

Conflict of interest. The authors declare that they have no conflict of interest.

\section{References}

Abraham WT, Raynolds MV, Badesch DB, Wynne KM, Groves BM, Roden RL, Robertson AD, Lowes BD, Zisman LS, Voelkel NF, Bristow MR, Perryman MB (2003): Angiotensin-converting enzyme DD genotype in patients with primary pulmonary hypertension: increased frequency and association with preserved haemodynamics. J. Renin Angiotensin Aldosterone Syst. 4, 27-30 https://doi.org/10.3317/jraas.2003.003

Ahn BH, Park HK, Cho HG, Lee HA, Lee YM, Yang EK, Lee WJ (2003): Estrogen and enalapril attenuate the development of right ventricular hypertrophy induced by monocrotaline in ovariectomized rats. J. Korean Med. Sci. 18, 641-648 https://doi.org/10.3346/jkms.2003.18.5.641

Alvarez BV, Pérez NG, Ennis IL, Camilión de Hurtado MC, Cingolani HE (1999): Mechanisms underlying the increase in force and $\mathrm{Ca}(2+)$ transient that follow stretch of cardiac muscle: a possible explanation of the Anrep effect. Circ. Res. 85, 716-722 https://doi.org/10.1161/01.RES.85.8.716

Bal E, Ilgin S, Atli O, Ergun B, Sirmagul B (2013): The effects of gender difference on monocrotaline-induced pulmonary hypertension in rats. Hum. Exp. Toxicol. 32, 766-774 https://doi.org/10.1177/0960327113477874

Barritt G, Rychkov G (2005): TRPs as mechanosensitive channels. Nat. Cell Biol. 7, 105-107 https://doi.org/10.1038/ncb0205-105

Bluhm WF, Sung D, Lew WYW, Garfinkel A, McCulloch AD (1998): Cellular mechanisms for the slow phase of the Frank-Starling response. J. Electrocardiol. 31 (Suppl), 13-22 https://doi.org/10.1016/S0022-0736(98)90273-4

Calaghan S, White E (2004): Activation of $\mathrm{Na}+\mathrm{H}+$ exchange and stretch-activated channels underlies the slow inotropic response to stretch in myocytes and muscle from the rat heart. J. Physiol. 559, 205-214

https://doi.org/10.1113/jphysiol.2004.069021

Caminhotto RO, Sertié RA, Andreotti S, Campaãa AB, Lima FB (2016): Renin-angiotensin system blockers regulate the metabolism of isolated fat cells in vitro. Braz. J. Med. Biol. Res. 49, pii: S0100-879X2016000800608 https://doi.org/10.1590/1414-431X20165409

Cingolani HE, Alvarez BV, Ennis IL, Camilión de Hurtado MC (1998): Stretch-induced alkalinization of feline papillary muscle: an autocrine-paracrine system. Circ. Res. 83, 775-780 https://doi.org/10.1161/01.RES.83.8.775 
Cingolani OH, Pérez NG, Ennis IL, Alvarez MC, Mosca SM, Schinella GR, Escudero EM, Cónsole G, Cingolani HE (2011): In vivo key role of reactive oxygen species and NHE-1 activation in determining excessive cardiac hypertrophy. Pflügers Arch. 462, 733-743 https://doi.org/10.1007/s00424-011-1020-8

Cingolani HE, Pérez NG, Cingolani OH, Ennis IL (2013): The Anrep effect: 100 years later. Am. J. Physiol. Heart Circ. Physiol. 304, H175-H182 https://doi.org/10.1152/ajpheart.00508.2012

Díaz RG, Pérez NG, Morgan PE, Villa-Abrille MC, Caldiz CI, Nolly MB, Portiansky EL, Ennis IL, Cingolani HE (2014): Myocardial mineralocorticoid receptor activation by stretching and its functional consequences. Hypertension 63, 112-118 https://doi.org/10.1161/HYPERTENSIONAHA.113.01726

Ennis IL, Aiello EA, Cingolani HE, Perez NG (2013): The autocrine/ paracrine loop after myocardial stretch: mineralocorticoid receptor activation. Curr. Cardiol. Rev. 9, 230-240 https://doi.org/10.2174/1573403X113099990034

Hongo K, White E, Le Guennec JY, Orchard CH (1996): Changes in $[\mathrm{Ca} 2+] \mathrm{i},[\mathrm{Na}+] \mathrm{i}$ and $\mathrm{Ca} 2+$ current in isolated rat ventricular myocytes following an increase in cell length. J. Physiol. 491, 609-619 https://doi.org/10.1113/jphysiol.1996.sp021243

Ito H, Hirata Y, Adachi S, Tanaka M, Tsujino M, Koike A, Nogami A, Murumo F, Hiroe M (1993): Endothelin-1 is an autocrine/ paracrine factor in the mechanism of angiotensin II-induced hypertrophy in cultured rat cardiomyocytes. J. Clin. Invest. 92, 398-403 https://doi.org/10.1172/JCI116579

Kentish JC, Wrzosek A (1998): Changes in force and cytosolic Ca2+ concentration after length changes in isolated rat ventricular trabeculae. J. Physiol. 506, 431-444 https://doi.org/10.1111/j.1469-7793.1998.431bw.x

Kockskämper J, von Lewinski D, Khafaga M, Elgner A, Grimm M, Eschenhagen T, Gottlieb PA, Sachs F, Pieske B (2008): The slow force response to stretch in atrial and ventricular myocardium from human heart: functional relevance and subcellular mechanisms. Prog. Biophys. Mol. Biol. 97, 250-267 https://doi.org/10.1016/j.pbiomolbio.2008.02.026

Lookin O, Kuznetsov D, Protsenko Y (2015a): Sex differences in stretch-dependent effects on tension and $\mathrm{Ca} 2+$ transient of rat trabeculae in monocrotaline pulmonary hypertension. J. Physiol. Sci. 65, 89-98 https://doi.org/10.1007/s12576-014-0341-8

Lookin O, Balakin A, Kuznetsov D, Protsenko Y (2015b): The length-dependent activation of contraction is equally impaired in impuberal male and female rats in monocrotaline-induced right ventricular failure. Clin. Exp. Pharmacol. Physiol. 42, 1198-1206 https://doi.org/10.1111/1440-1681.12471

Malhotra R, Sadoshima J, Brosius FC, Izumo S (1999): Mechanical stretch and angiotensin II differentially upregulate the renin-angiotensin system in cardiac myocytes in vitro. Circ. Res. 85, 137-146 https://doi.org/10.1161/01.RES.85.2.137

Monasky MM, Biesiadecki BJ, Janssen PM (2010): Increased phosphorylation of tropomyosin, troponin I, and myosin light chain-2 after stretch in rabbit ventricular myocardium under physiological conditions. J. Mol. Cell Cardiol. 48, 1023-1028 https://doi.org/10.1016/j.yjmcc.2010.03.004

Neves JS, Castro-Ferreira R, Ladeiras-Lopes R, Neiva-Sousa M, Leite-Moreira AM, Almeida-Coelho J, Fontes-Carvalho R, Ferreira-Martins J, Leite-Moreira AF (2013): The effects of angiotensin II signaling pathway in the systolic response to acute stretch in the normal and ischemic myocardium. Peptides $47,77-84$ https://doi.org/10.1016/j.peptides.2013.07.004

Pérez NG, Villa-Abrille MC, Aiello EA, Dulce RA, Cingolani HE, Camilion de Hurtado MC (2003): A low dose of angiotensin II increases inotropism through activation of reverse $\mathrm{Na}+\mathrm{Ca} 2+$ exchange by endothelin release. Cardiovasc. Res. 60, 589-597 https://doi.org/10.1016/j.cardiores.2003.09.004

Pérez NG, Nolly MB, Roldan MC, Villa-Abrille MC, Cingolani E, Portiansky EL, Alvarez BV, Ennis IL, Cingolani HE (2011): Silencing of NHE-1 blunts the slow force response to myocardial stretch. J. Appl. Physiol. 111, 874-880

https://doi.org/10.1152/japplphysiol.01344.2010

Sadoshima J, Xu Y, Slayter HS, Izumo S (1993): Autocrine release of angiotensin II mediates stretch-induced hypertrophy of cardiac myocytes in vitro. Cell 75, 977-984 https://doi.org/10.1016/0092-8674(93)90541-W

Seo K, Rainer PP, Shalkey HV, Lee DI, Jo SH, Andersen A (2014): Combined TRPC3 and TRPC6 blockade by selective smallmolecule or genetic deletion inhibits pathological cardiac hypertrophy. Proc. Natl. Acad. Sci. USA 111, 1551-1556 https://doi.org/10.1073/pnas.1308963111

Shao Q, Saward L, Zahradka P, Dhalla NS (1998): Ca2+ mobilization in adult rat cardiomyocytes by angiotensin type 1 and 2 receptors. Biochem. Pharmacol. 55, 1413-1418 https://doi.org/10.1016/S0006-2952(97)00653-9

Shen X, Cannell MB, Ward ML (2013): Effect of SR load and $\mathrm{pH}$ regulatory mechanisms on stretch-dependent $\mathrm{Ca} 2+$ entry during the slow force response. J. Mol. Cell Cardiol. 63, 37-46 https://doi.org/10.1016/j.yjmcc.2013.07.008

Todaka K, Ogino K, Gu A, Burkhoff D (1998): Effect of ventricular stretch on contractile strength, calcium transient, and cAMP in intact canine hearts. Am. J. Physiol. Heart Circ. Physiol. 274, H990-H1000

https://doi.org/10.1152/ajpheart.1998.274.3.H990

Thomas GP, Ferrier GR, Howlett SE (1996): Losartan exerts antiarrhythmic activity independent of angiotensin II receptor blockade in simulated ventricular ischemia and reperfusion. J. Pharmacol. Exp. Ther. 278, 1090-1097

van Wamel AJ, Ruwhof C, van der Valk-Kokshoorn LJ, Schrier PI, van der Laarse A (2000): Rapid effects of stretched myocardial and vascular cells on gene expression of neonatal rat cardiomyocytes with emphasis on autocrine and paracrine mechanisms. Arch. Biochem. Biophys. 381, 67-73 https://doi.org/10.1006/abbi.2000.1947

Vargas LA, Díaz RG, Swenson ER, Pérez NG, Álvarez BV (2013): Inhibition of carbonic anhydrase prevents the $\mathrm{Na}+\mathrm{H}+\mathrm{ex}-$ changer 1-dependent slow force response to rat myocardial stretch. Am. J. Physiol. 305, H228-H237 https://doi.org/10.1152/ajpheart.00055.2013 
von Lewinski D, Stumme B, Maier LS, Luers C, Bers DM, Pieske B (2003): Stretch-dependent slow force response in isolated rabbit myocardium is $\mathrm{Na}+$ dependent. Cardiovasc. Res. 57, 1052-1061

https://doi.org/10.1016/S0008-6363(02)00830-1

von Lewinski D, Stumme B, Fialka F, Luers C, Pieske B (2004): Functional relevance of the stretch-dependent slow force response in failing human myocardium. Circ. Res. 94, 1392-1398 https://doi.org/10.1161/01.RES.0000129181.48395.ff

von Lewinski D, Kockskamper J, Zhu D, Post H, Elgner A, Pieske B (2009): Reduced stretch-induced force response in failing human myocardium caused by impaired $\mathrm{Na}+$-contraction coupling. Circ. Heart Fail. 2, 47-55 https://doi.org/10.1161/CIRCHEARTFAILURE.108.794065

Yamaguchi Y, Iribe G, Kaneko T, Takahashi K, Numaga-Tomita T, Nishida M, Birnbaumer L, Naruse K (2018): TRPC3 par- ticipates in angiotensin II type 1 receptor-dependent stressinduced slow increase in intracellular $\mathrm{Ca} 2+$ concentration in mouse cardiomyocytes. J. Physiol. Sci. 68, 153-164 https://doi.org/10.1007/s12576-016-0519-3

Yasuda N, Akazawa H, Qin Y, Zou Y, Komuro I (2008): A novel mechanism of mechanical stress-induced angiotensin II type 1-receptor activation without the involvement of angiotensin II. Naunyn Schmiedebergs Arch. Pharmacol. 377, 393-399 https://doi.org/10.1007/s00210-007-0215-1

Zeng T, Bett GC, Sachs F (2000): Stretch-activated whole cell currents in adult rat cardiac myocytes. Am. J. Physiol. Heart Circ. Physiol. 278, H548-H557

https://doi.org/10.1152/ajpheart.2000.278.2.H548

Received: May 22, 2017

Final version accepted: June 22, 2017 